\title{
A mindful path to the COVID-19 pandemic: An approach to promote physical distancing behavior
}

\author{
Sachin Kumar \\ Doctoral Research Fellow, Jindal Global Business School, O.P. Jindal Global University, \\ Sonipat, Haryana, India. \\ (sachin.vrin@gmail.com) \\ Prof. (Dr.) Tapan K. Panda
}

Professor and Director, Narsee Monjee Institute of Management Studies, Hyderabad, India.

(tapanpanda@gmail.com)

Prof. (Dr.) Anil Kumar

Post-Doctoral Research Fellow, Derby Business School, University of Derby, United Kingdom (UK).

Prof. (Dr.) Abhishek Behl

SCMHRD, Symbiosis International University, Pune, India.

\begin{abstract}
Purpose - The present situation is marked by the threat of the COVID-19 pandemic on entire humankind and researchers across the globe are looking forward to vaccines or medicines to tackle COVID-19. But, according to the scholars and health care agencies, vaccines alone won't be of much help, and in the long run adhering to the physical distancing policy along with sanitation could be the only solution. Moreover, extant studies across different areas have noted a positive association between various human psychological factors and prosocial behaviours. Additionally, an empirical study undertaken in the western context has tried exploring the association between a human psychological factor and physical distancing behaviour (a kind of prosocial behaviour) in the COVID19 context. The results of the extant study seem intriguing and encouraging enough to undertake a more robust exploratory study in this nascent area. Against this background, the present study intends to explore the relationship between individuals' mindfulness and physical distancing behaviour, along with the mediating role of empathy during the COVID-19 pandemic.
\end{abstract}

Design/methodology/approach - To achieve the study objectives, this study has utilized an online survey method and has collected responses from the general adult population in India spread across all the six regions. The survey was conducted during May 2020 when India was under a nationwide lockdown to mitigate the risk of COVID-19 pandemic. The respondents were identified based on the convenience and snowball sampling techniques and utilizing social media platforms the prospective respondents were either contacted through WhatsApp, LinkedIn, and Facebook or e-mails. Post data cleaning, a total of 315 responses were found to be suitable for analysis. For analysis, confirmatory factor analysis was conducted to establish the validity and reliability of the conceptual model, whereas Pearson correlation was undertaken to study the relationship between variables, and mediation was examined using the PROCESS macro of Hayes. 
Findings - The findings were encouraging and could become the foundation stone for further research as well as a practical guide for policymakers, agencies working in the healthcare areas, and even corporate leaders. As expected, an individual's mindfulness was noted to be positively related and influencing physical distancing behaviour and the mediation analysis indicated the intervening role of empathy in the association between an individual's mindfulness and physical distancing behaviour.

Theoretical implications - This study relates and extends the mechanism of mindfulness in influencing individuals' physical distancing behaviour in the pandemic situation, notably the COVID19 pandemic. Moreover, based on the "empathy-altruism hypothesis" as well as Schwartz's theory of basic values, the intervening role of empathy has been explored and the findings further helped in extended these two theories in the domain of pandemic.

Practical implications - The findings of the present could be a game-changer in restricting the spread of the COVID-19 pandemic. As espoused by various scholars as well as health care organizations about the usefulness of physical distancing in mitigating the risk of COVID-19, policy makers, healthcare authorities, and even corporate leaders could look forward to strategizing and executing the dissemination of various mindfulness-based programs amongst the individuals. These mindfulnessbased programs, which could be disseminated offline as well as online through smartphones, could inturn help in positively influence physical distancing behaviour amongst the individuals leading to the success of physical distancing policy.

Originality/value - This study could be the first to conceptualize and examine the human psychological factors, particularly the relationship and the role of an individual's mindfulness with that of physical distancing behaviour amongst the general public during the COVID-19 pandemic. Additionally, this could also be the first study to conceptualize and explore the intervening role of empathy in the relationship between an individual's mindfulness and physical distancing behaviour. Moreover, in conceptualizing and exploring the relationship between an individual's mindfulness and physical distancing behaviour, this study explored and extended the "reperceiving" mechanism of mindfulness and the "empathy-altruism hypothesis" along with Schwartz's theory of basic values in the domain of pandemic.

Keywords: Mindfulness, physical distancing behaviour, physical distancing policy, social distancing behaviour, empathy, coronavirus, Covid-19, pandemic. 
"SARS CoV-19 is only getting stronger with every passing month..., scientists from World Health Organisation are now saying that pinning our hopes on a vaccine alone won't solve the crisis at large..., for the long run, the only thing that can help lower down the spread is practicing effective social distancing and sanitation where possible" (Times of India, 2020).

\section{Introduction}

Pneumonia of unknown etiology was first reported in the Wuhan city of China in December 2019 (Holshue et al., 2020), and by March 2020 it rapidly spread across the globe affecting 114 countries (World Health Organization, 2020a).The causative agent behind this pneumonia was identified to be a virus (a novel coronavirus, SARS-CoV-2; Wilder-Smith et al., 2020), named as COVID-19, and was declared a pandemic by the World Health Organization (WHO) on $11^{\text {th }}$ March 2020 (World Health Organization, 2020a).

Since its first appearance, the COVID-19 pandemic has spread across the globe, affecting individuals at an exceptionally faster pace (Fischer et al., 2020; Pennycook et al., 2020). As of $28^{\text {th }}$ July 2020, COVID-19 has spread across 216 countries or territories with more than 16.34 million cases of infected people, and around 0.65 million of confirmed reported deaths. The top three countries/territories facing the maximum issues of COVID-19 infection are the United States of America (USA) reporting maximum cases with more than 4.20 million infected people, along with approximately 0.14 million of deaths. Similarly, Brazil reported 2.41 million infected and 87,004 deaths, and India reported 1.48 million confirmed infected cases, along with 33,423 deaths (World Health Organization, 2020b). The spread of infection, as well as the death rates, is frightening, and the cases are rising day by day.

According to the researchers, the COVID-19 infection is spreading at such a phenomenal rate because of its high rate of reproductive number (R0) (for details, please refer to Sen-Crowe et al., 2020). The R0 is defined as the number of secondary infections caused by an infected individual, and an R0 value of $>1$ leads to increased spread in disease. In the case of COVID-19, the average R0 is estimated at 3.3, hence a continued faster spread of infection (Liu et al., 2020). Furthermore, according to the scholars, apart from factors (biological, environmental, etc.) related to the virus, the R0 is a function of human "social behaviour" and depends on the duration of time an individual spends with other individuals (Delamater et al., 2019). Looking into the relationship of R0 with the human contact factor, 
researchers have argued about changing the way an individual comes into contact with other individuals to check the spread of COVID-19.

Furthermore, the Centers for Disease Control and Prevention (CDC) recommended people to stay at home and avoid close contacts with others (should maintain a distance of 6 feet) to avoid contacting COVID-19 infection (Canning et al., 2020; Centers for Disease Control and Prevention, 2020). Such a phenomenon where an individual maintains distance with other individuals to avoid or decrease the chance of getting infected, i.e., reducing the likelihood of interpersonal transmission, has been termed as "social distancing" or "physical distancing" (Anderson et al., 2020; Bai et al., 2020; Centers for Disease Control and Prevention, 2020). The WHO initially referred to "physical distancing" as "social distancing" but latter endorsed using "physical distancing" (Pfattheicher et al., 2020). Moreover, WHO scientists are of the view that in the case of COVID-19 pandemic vaccines alone won't be of much help (despite researchers' war-footing effort across the globe to develop vaccines for COVID-19) and in the longer run practising physical distancing along with sanitation could be the only solution to slow down the spread of COVID-19 (Times of India, 2020). Additionally, in their systematic review, (Bults et al., 2015) noted the effectiveness of physical distancing and the role of the general public in minimizing and controlling the spread of the pandemic. They stated, "hygienic practices" and "physical distancing" undertaken by the general public as the most reported preventive behaviors across several studies conducted in different cultural contexts. Similarly, the decisive role of physical distancing in restricting the spread of COVID-19 has also been reported by Hsiang et al. (2020), and scholars have advocated immediate as well as intermittent long term physical distancing policy in restricting the spread of COVID-19 (Ferguson et al., 2020; Gostin and Wiley, 2020). Others studies have also noted the usefulness of physical distancing in checking the spread of epidemic (Glass et al., 2006; Poletti et al., 2009), and scholars have also discussed the effectiveness of physical distancing behaviour in one of the deadliest pandemic, the 1918 Spanish flu (Bootsma and Ferguson, 2007; Caley et al.,2008). Moving a step ahead, researchers like Fong et al. (2020) argued that "social distancing measures will be useful components of the public health response to the next pandemic" (p 982).

Thus, from the preceding discussion, it could be concluded that scholars have argued about the importance of physical distancing in restricting the spread of the COVID-19, and physical distancing seems to have emerged as the primary line of defence to fight and check 
the spread of COVID-19 (Long, 2020; Sen-Crowe et al., 2020). Adhering to the physical distancing policy by the general public seems to be the most effective strategy in managing the spread of COVID-19 pandemic (Milne and Xie, 2020). Moreover, governments across the globe have called for and have undertaken steps to implement physical distancing behaviour amongst the public (Canning et al., 2020; Cohen, 2020; Fisher and Wilder-Smith, 2020; Helmich and Bloem, 2020; Lewnard and Lo, 2020; Mahase, 2020). Authorities are following a mix of strategies, both encouragement and coercive, in making people adhere to the physical distancing policy (Pfattheicher et al., 2020). But, despite the appeal by various stakeholders (authorities, politicians, healthcare professionals, celebrities, religious leaders, etc.) to the general public to avoid public gatherings and adhere to physical distancing (McCloskey et al., 2020) to slow down the spread of COVID-19 (Milne and Xie, 2020), many individuals seem to be ignoring this and not adhering to the physical distancing policy (Roy et al., 2020). The non-adherence to the physical distancing policy by the general public during the COVID-19 pandemic crisis seems strange. Moreover, exploring human psychological factors that could augment physical distancing behaviour amongst individuals leading to the success of the physical distance policy and mitigate the spread of this global pandemic is warranted (Pennycook et al., 2020).

Furthermore, a few of the studies conducted in the recent past have tried exploring and have also emphasized the factors which could have been influencing compliance towards adhering to the physical distancing behaviour (for details, please refer to Brzezinski et al., 2020). Factors like "political ideology" (Allcott et al., 2020; Painter and Qiu, 2020; Pennycook et al., 2020), "poverty and economic dislocation" (Wright et al., 2020), "belief about science" (Brzezinski et al., 2020), and demographic characteristic like age (Canning et $a l ., 2020)$ are noted to be influencing physical distancing behaviour. Moreover, despite the role of human behaviour in spreading the COVID-19 pandemic (Delamater et al., 2019), there is hardly any research focusing on human psychological aspects, especially those which could help in augmenting physical distancing behaviour amongst individuals to mitigate the spread of this pandemic. The non-availability of human psychology studies could be justified as the Coronavirus COVID-19 issue is in existence for around six months only. To the best of our knowledge, only one empirical research (for details, please refer Pfattheicher et al., 2020) has tried exploring the human psychological motives behind engaging in physical distancing behaviour during the COVID-19 pandemic. The study by Pfattheicher et al. (2020) tested the association between empathy and physical distancing behaviour in the western context and 
noted a positive relationship. In their study, physical distancing behaviour has been conceptualized both as benefitting self as well as others, especially a behaviour targeted towards "helping and protecting vulnerable others." Moreover, getting involved in and adhering to the act of physical distancing behaviour is conceptualized as a prosocial act because of its orientation towards helping and protecting others, particularly those who are most susceptible to the COVID-19 pandemic (Pfattheicher et al., 2020). Additionally, a call to undertake a similar study in a different context and even testing other human psychological factors influencing physical distancing behaviour was made (Pfattheicher et al., 2020).

Thus, it could be inferred that the present situation is marked by the threat of Coronavirus Covid-19 on the existence of humankind. In the absence of any medicines or vaccines, the situation is getting worsens. In such a gloomy situation, any human psychological based approach such as those related to the behavioural augmentation promoting physical distancing behaviour among individuals, which has been argued to slow down the spread of the COVID-19 pandemic by helping individuals adhere to the physical distancing policy, could prove to be a "holy grail."

Building on the existing concepts and scholarly works in the domain of human psychology, human behaviour etc. and against the backdrop of the above developments, we tested whether an individual's mindfulness could be associated with and influence physical distancing behaviour, a prosocial behavior targeted towards protecting others who are most susceptible to the COVID-19 pandemic. This study was conceptualized and aimed to empirically test whether (1) an individual's mindfulness is positively related to physical distancing behaviour, and (ii) whether empathy towards individuals most susceptible to the coronavirus COVID-19 mediates the association between an individual's mindfulness and physical distancing behaviour.

Mindfulness has its roots in Buddhist philosophy is delineated as "paying attention in a particular way: on purpose, in the present moment and non-judgmentally. This kind of attention nurtures greater awareness, clarity, and acceptance of present-moment reality" (Kabat-Zinn, 1994, p. 4). It is the "process by which we go about deepening our attention and awareness, refining them and putting them to greater practical use in our lives" (p. xvii). Thus, mindful individuals can generate unbiased multiple perspectives of the incidences around them (Kabat-Zinn, 1990), and can cultivate others oriented compassion and empathy 
(Khoury et al., 2017). Even scholarly work in the area of "mindfulness theory" (e.g. BlockLerner et al., 2007; Ridderinkhof et al., 2017; Trautwein et al., 2014), and other empirical publications (e.g. Condon et al., 2013; Lim et al., 2015) have argued about the role of mindfulness in augmenting others oriented behaviours. Moreover, across different studies, scholars have also argued about the role of empathy in promoting others oriented behaviours towards both known, as well as strangers (Carlo et al., 2011; Padilla-Walker and Christensen, 2011). Additionally, across a series of studies, including experiments, the intervening role of empathy was noted between the positive association of mindfulness with prosocial behaviour (Berry et al., 2018).

Thus, amidst a handful of existing studies (either in the conceptual or pilot stage) trying to explore the human psychological factors in tackling the COVID-19 pandemic, along with the established scholarly work on the relationship amongst mindfulness, empathy, and prosocial behaviours, the present study could be the first one to empirically investigate the association among individual's mindfulness, empathy, and physical distancing behaviour in COVID-19 context.

This study was undertaken during the nationwide lockdown period amongst the adult Indian population residing in any six regions of India and aimed to contribute in the following ways. First and foremost, it explores the effect of an individual's mindfulness on physical distancing behaviour. Second, it looks at the possibility of empathy as a mediating factor between an individual's mindfulness and physical distancing behaviour. Finally, this study could be the first to empirically explore the influence of individuals' mindfulness on physical distancing behaviour directly as well as through the mediation effect of empathy.

The subsequent segments of this study are structured as follows: first and foremost, we have briefed mindfulness and empathy along with the mechanism through which mindfulness and empathy are thought to bring in the positive effects and could be related to others' oriented behaviours. Then a brief discussion about the existing conceptual as well as empirical studies that forms the basis of the arguments upon which conceptual framework and hypotheses have been built is provided. Next, a whole section is devoted to a research design that details the process of selecting the appropriate measures along with the designing of the survey instrument. Details about the data collection procedure and sampling have been also provided. In the analysis and results section, details of exploratory factor analysis, 
confirmatory factor analysis along with the details on scale validation, descriptive analysis and mediation analysis using PROCESS macros is provided. The study concludes by discussing the findings along with the theoretical and practical implications, limitations, and future research directions.

\section{Theoretical underpinning and hypotheses development}

Consistent with the extant scholarly works, mindfulness is described as "paying attention in a particular way, on purpose, in the present moment, and non-judgmentally". This kind of attention nurtures greater awareness, clarity, and acceptance of present-moment reality" (Kabat-Zinn, 1994, p. 4). Additionally, mindfulness is thought to include an "affectionate, compassionate quality within the attending, a sense of openhearted, friendly presence and interest" (Kabat-Zinn, 2003, p. 145). Moreover, the cultivation of mindfulness is thought to leads to the cultivation of self and "others oriented" intentions and attitudes like benevolence, concern for others and generosity (Grossman, 2015). It is believed to be "a universal human ability embodied to foster clear thinking and open-heartedness," requiring no particular religious or cultural belief (Trousselard et al., 2014, p. 475), helping individuals to have "open and creative" attention to one's surroundings allowing individuals to avoid routinized and habituated behaviours (Langer, 2005).

Furthermore, Guendelman et al. (2017), argued about the models trying to explain the mechanism through which mindfulness brings about positive changes. Here, the "reperceiving" mechanism of mindfulness proposed by Shapiro et al. (2006) is worth briefing because of its wide acceptance and also being supported by the contemporary models including the neurocognitive model (for details, please see Holzel et al., 2011; Vago and Silbersweig, 2012). According to Shapiro et al. (2006), the "reperceiving" mechanism could be explained as a developmental process wherein "individuals can shift their perspective away from the narrow and limiting confines of their points of reference" (p. 378), and allows for "a deep, penetrative non-conceptual seeing into the nature of mind and world" (KabatZinn, 2003, p. 146). The process of reperceiving brings in a "profound shift in one's relationship to thoughts and emotions" and is thought to bring in transformations fostered with the help of mindfulness practice. Moreover, reperceiving acts as a facilitator enabling adaptation in perspective and also allows "cognitive, emotional, and behavioural flexibility", leading to change and positive outcomes (Shapiro et al., 2006). Individuals can augment their 
coping skills by purposefully nurturing consciousness and acceptance to get familiar with the current moment. When acting mindfully, the behaviours are more aligned with the authentic needs and values (Brown and Ryan, 2003), and individuals can choose the significant benefits, as the process of reperceiving has helped recognize the meaningful real value (Shapiro et al., 2006).

Extant scholarly works in the area of mindfulness have argued about the positive role of mindfulness in promoting empathy (e.g. Shapiro et al.,1998; Wallmark et al., 2013; Winning and Boag, 2015). Similarly, across systematic review including meta-analysis, the positive effects of mindfulness oriented meditation on empathy were also noted (Cahn and Polich, 2006; Luberto et al., 2018).

Furthermore, empathy is considered to be one of the "building blocks of moral behaviour" nurturing others oriented motivation and behaviour (Batson, 2010; Eisenberg, 2000). A considerable number of existing scholarly articles across various research domains have noted a positive association between empathy and prosocial behaviours in a variety of situation (Eisenberg and Miller, 1987; Dovidio et al., 1990; McMahon et al., 2006; Morelli et al., 2014; Telle and Pfister, 2016). Moreover, apart from the existing empirical research, the relation between empathy and prosocial behaviour could be underpinned on the following theoretical arguments. First, the relationship between empathy and others oriented behaviour could be explained based on "empathy-altruism hypothesis" which states the role of empathy in promoting the welfare of others (for details on the "empathy-altruism hypothesis", please refer Batson, 2010). Secondly, in accordance with the Schwartz's theory of basic values, selftranscendence values (e.g., benevolence values) are linked to concern and the welfare of others (Schwartz, 1992), and were also observed to be related to high levels of empathy (Pohling et al., 2016). Moreover, universalism (augmenting well-being for humankind) and benevolence values have been noted for showing welfare for others (Schwartz, 1994), and been shown to be strongly related to empathy (Balliet et al., 2008; Myyrya et al., 2010; Roccas et al., 2002). Thus, based on the above scholarly work it could be inferred that empathy nurtures and promotes prosocial behaviour.

Individual'smindfulness and physical distancing 
Extant studies stated about the role of mindfulness in influencing an individual's natural connectedness with others (Davidson and Harrington, 2002), and is thought to happen by moving individuals away from their only self-concerns (Good et al., 2016). Mindfulness is said to enable others oriented behaviour because it facilitates individuals to connect to their own as well as others experience happening in the current moment and also the immediate focus attention helps in a nuanced understanding of the situation (Decety and Ickes, 2011; Holzel et al., 2011). Similarly, in their conceptual article, Ericson et al. (2014) also argued mindfulness to be a pre-requisite of prosocial behaviour. Moreover, extant empirical studies have also noted the decisive role of mindfulness in prosocial behaviours like "improved intimate relationships" (Barnes et al., 2007), "openness, relatedness, and interpersonal closeness" (Brown and Ryan, 2003), “others' emotional experiences” (Farb et al., 2007) and others centred behaviours (Krasner et al., 2009). Additionally, in a systematic review and meta-analytic study, mindfulness was noted to be positively related to other-oriented behaviour (Donald et al., 2019). Moreover, in line with the reperceiving mechanism, mindfulness is thought to enhance other's oriented behaviours, and individuals high on mindfulness have shown prosocial behaviours (Holzel et al., 2011; Shapiro et al., 2006).

Furthermore, physical distancing behaviour has been conceptualized both as benefitting self as well as others, especially a behaviour targeted towards "helping and protecting vulnerable others." Moreover, getting involved in and adhering to the act of physical distancing behaviour is conceptualized as a prosocial act because of its orientation towards helping and protecting others, particularly those who are most susceptible to the COVID-19 pandemic (Pfattheicher et al., 2020). Thus, based on the above arguments it can be hypothesized that:

H1: Individual's mindfulness is positively related to physical distancing behaviour during coronavirus COVID 19 pandemic.

\section{Individual'smindfulness and empathy}

Empathy is "the capacity to (a) be affected by and share the emotional state of another, (b) assess the reasons for the other's state, and (c) identify with the other, adopting his or her perspective" (De Waal, 2008, p. 281). Moreover, as a necessary "socio-emotional process of human development" empathy, involves an individual's ability to take notice of 
others perspectives (Richaud et al., 2017), and individuals can work towards benefiting others as they can steer out of the "survival mode" (Siegel, 2007). Additionally, empathetic individuals can connect with the emotions of others irrespective of the nature of the feelings (Hafenbrack et al., 2019).

Furthermore, theorists argue about mindfulness fostering empathy (Block-Lerner et al., 2007; Kristeller and Johnson, 2005; Neff, 2003; Ridderinkhof et al., 2017), and practising mindfulness have been noticed to activate the regions of the brain which are known to get activated during empathy (Fan et al., 2011). Similarly, according to the reperceiving mechanism, mindfulness helps in balancing the emotions and also values clarification. Individuals high on mindfulness can control their feelings and act according to their actual intrinsic values (Holzel et al., 2011; Shapiro et al., 2006). Extant studies have noticed the positive influence of mindfulness intervention on empathy (Jazaieri et al., 2013; Klimecki et al., 2013; Tan et al., 2014). After participating in mindfulness-based meditation programs, an increased level of empathy has been noticed in the participants (Bellosta-Batalla et al., 2020; Shapiro et al., 1998). Additionally, individuals reporting high on mindfulness were also observed to have reported an increased level of empathy (Dekeyser et al., 2008; Shapiro et al., 2011). Thus, it can be hypothesized that:

H2: Individual'smindfulness is positively related to empathy for those most susceptible to coronavirus COVID 19.

Individual's mindfulness, Empathy, and physical distancing

The property of mindfulness, namely "present focus attention," is known to help individuals live in the "present moment" and align their own needs with the needs of the others. Moreover, the attention focus also allows individuals to empathize with other's needs (Decety and Ickes, 2011; Good et al., 2016; Holzel et al., 2011). Similarly, a plethora of extant studies unravels the decisive role of empathy in promoting a wide range of prosocial and others oriented behaviours (Eisenberg et al., 2006; Prot et al., 2014; Richaud et al., 2017; Williams et al., 2014).

Moreover, Pfattheicher et al. (2020) conducted multiple studies during the recent COVID-19 pandemic outbreak on samples from three nations (the US, the UK, and 
Germany). They noted the decisive role of empathy in physical distancing behaviour (a prosocial behaviour), and that "empathy for those most vulnerable to the virus" was found to be the primary motivation for adhering to physical distancing.

Furthermore, according to the reperceiving mechanism, mindfulness brings in positive effects by either acting directly or through intervening processes like "self-regulatory control," "values clarification" and "cognitive, emotional, and behavioral flexibility" (Shapiro et al., 2006). Similarly, in their conceptual study on "mindfulness at work," Glomb et al. (2011) stated the role of empathy through which mindfulness enacts its positive effects, and individuals could act to improve the situation of others by getting involved in others oriented behaviours (Dutton et al., 2014). Additionally, in cross-cultural multiple field experiments conducted in the US and India, Hafenbrack et al. (2019) noted a positive relationship between mindfulness and prosocial behaviour, i.e., mindfulness influences others oriented expression. They further argued that empathy has a fundamental role in this relationship and that mindfulness could foster added prosocial behaviour "through the mechanism of increased empathy", and that increased empathy mediated that positive relationship between mindfulness and prosocial behaviour (Hafenbrack et al., 2019). Similarly, across multiple studies including meta-analysis, Berry at al. (2018) concluded the intervening role of empathy in the positive association between mindfulness and prosocial behaviour. Therefore, it can be hypothesized that:

H3: Empathy for those most susceptible to coronavirus COVID 19 mediates the relationship between an individual's mindfulness and physical distancing behaviour.

\section{Research design}

\subsection{Measures}

Individual's mindfulness - Individual's mindfulness was recorded using a short form of "Mindfulness Attention and Awareness Scale" MAAS (Brown and Ryan, 2003; Van Dam et al., 2010). It is a widely used scale to access mindfulness. The sample items include, "It seems I am 'running on automatic' without much awareness of what I'm doing." and "I get so focused on the goal I want to achieve that I lose touch with what I am doing right now to get there." Respondents were asked to record their responses for the five items on a 5-point 
Likert response scale $(1=$ never; 5 = always $)$. The analysis was done by reversing the responses so that the respondents high on mindfulness scores reflect greater mindfulness. Extant studies reported high Cronbach alpha, and the current sample also confirmed good internal consistency (an alpha of .720).

Empathy - Empathy for those most vulnerable to COVID 19 was measured using three items. These three items have been earlier used by Pfattheicher et al. (2020) in a study on coronavirus pandemic. These three items were borrowed and adapted for the coronavirus pandemic study (for details, please refer to Pfattheicher et al., 2020; Pfattheicher et al., 2019). The sample items of this measure include "I am very concerned about those most vulnerable to coronavirus COVID 19" and "I am quite moved by what can happen to those most vulnerable to coronavirus COVID 19". Respondents recorded their responses on a 5-point Likert response scale $(1=$ never; $5=$ always $)$. An earlier study has reported alpha in the range of .81 - .89, and high Cronbach alpha was also reported in the current sample (an alpha of . $803)$.

Physical distancing - Physical distancing was accessed using self-rated, two items scale developed by Pfattheicher et al. (2020) for their study on coronavirus pandemic. The sample items include "Because of coronavirus COVID-19, I am massively curtailing social contact (so-called "social distancing")" and "Because of coronavirus COVID-19, it is very important that others massively curtail social contact (so-called "social distancing")." Participants rated the items on a 5 -point Likert response scale $(1=$ never; 5 always $)$. High Cronbach alpha (.71) was reported in the recent study (Pfattheicher et al., 2020), and the current sample also confirmed good internal consistency (an alpha of .813).

\subsection{Sample and data collection procedure}

An online data collection platform SurveyMonkey (also used in earlier studies, e.g., Gallicano et al., 2012; Wallace et al., 2017) was utilized to design and administer the survey questionnaire. The survey instrument consisted of 15 questions, including three demographic items, namely gender, age, and present location of respondents. Moreover, five items for individual mindfulness, along with three items for empathy and two items for physical distancing, were included in the questionnaire. Additionally, one question related to "consent to participate" and an attention check question was also included. The survey was designed to 
encourage participants to willingly take-up the study with the required attention and could record their responses in around 3-4 minutes (Liu and Wronski, 2018). The participants were requested to register their responses on a 5-point Likert response scale ranging from "never" to refer Appendix 1 "always").

While designing the questionnaire, a few procedural remedies to tackle the common method bias (CMB) were followed (Podsakoff et al., 2003). The respondents were assured about the anonymity and confidentiality of their personal information. Moreover, the items of the exogenous and endogenous variables were placed on the separate pages of the survey to avoid respondents guessing cause-effect relationships. Additionally, an attention check question was also put helping in shorting and discarding responses that were recorded without paying much attention to the questions (Podsakoff et al., 2003).

The survey was conducted and the data was collected over six days (from $12^{\text {th }}$ May to $17^{\text {th }}$ May 2020). During this time, India was under nationwide locked down. People were appealed to and allowed to go out of their home only in cases of medical emergencies, to purchase medicines, and to buy essentials. Visit banks, ATMs, grocery stores, and petrol/gas stations were also allowed. All essential and emergency services were functioning, but physical distancing criteria, along with other safety measures related to coronavirus COVID19 pandemic, as chalked by the Indian government, were adhered to.

An online data collection technique was employed as it offers quick and easy access to population spread across larger areas (in the present study, across all six regions of India). The online survey also has the advantages of avoiding confounding sources along with the assurance of increased respondents' anonymity (Granello and Wheaton, 2004; Hewson and Charlton, 2005; Raat et al., 2007). Additionally, non-representative sampling techniques in the form of convenience, as well as snowball sampling, were utilized. Similar sampling procedures have been followed in recent studies on the coronavirus COVID-19 (e.g., Pfattheicher et al., 2020; Roy et al., 2020; Zhang and Ma, 2020). The reference population (prospective respondents) for the present study were adult Indian population (Indian citizens, both male and female, born between 1946 - 1999, residing in any part of India at the time of undertaking the survey), and were either contacted through social media (WhatsApp, LinkedIn, and Facebook) or e-mail. Extant studies support the reliability of social media and e-mail for reaching the targeted respondents (King et al., 2014), and even study in the domain 
of coronavirus COVID-19 have used this technique (e.g., Canning et al., 2020; Roy et al., 2020).

\section{Analysis and results}

395 prospective respondents opened the survey link, and 20 of them did not participate in the survey by clicking on "I do not wish to participate." The remaining 375 prospective participants clicked on "I wish to participate" and recorded their responses. First and foremost, data cleaning was undertaken for 375 respondents who participated in the survey. A total of 60 responses were dropped either because respondents did not attempt all the questions or because of the inattentive responses. A few responses were also not considered because of the "straight-lining" responses issues (Reiter, 2015). Post data cleaning, 315 responses (84 percent responses) were found fit and considered for the final analysis.

Furthermore, all three measures were subjected to Exploratory Factor Analysis (EFA) for refinement. This was followed by Confirmatory Factor Analysis (CFA) of all the three measures to estimate the constructs' validity and reliability along with the fitness of the measurement model. Additionally, the Common Method Bias (CMB) test was also done. The analysis was conducted using IBM SPSS and AMOS 23 statistical software package. As suggested, multiple indices of model fit like "Chi-square/df," "Comparative Fit Index" (CFI), “Tucker-Lewis Index" (TLI), "Incremental Fit Index" (IFI), and "Root Mean Square Error of Approximation" (RMSEA) were considered and reported. Moreover, as suggested by the scholars, the following values of the multiple indices of model fit (Chi-square/df $<3$; CFI, TLI, IFI > 0.90, and RMSEA < .08) suggesting good fit was considered (Hair et al., 1998, 2006).

The values of the Pearson correlation were considered to estimate the relationship between the variables, and the research hypotheses along with the mediator effect were tested utilizing the PROCESS macro of Hayes (2017). PROCESS macros is a robust regression approach aimed at mediation, moderation, and conditional process models analysis. Depending on the type of model to be estimated in a particular study, the researcher chooses a "pre-programmed" model type. Stepwise arguments and procedures facilitate the analysis including Sobel's statistics and bootstrap estimations. Statistical outcomes like path 
coefficients, std. errors, $\mathrm{t}$ and $\mathrm{p}$ values, and confidence intervals along with others are estimated.

\subsection{Demographic Characteristics}

Out of the valid responses considered in the current study, around 70 percent were recorded by males and the remaining 30 percent were female respondents. Moreover, the majority of the respondents, approximately 87 percent were from Gen Y/Millennial cohort, 12.7 percent belonged to Gen X, and only two respondents ( 0.6 percent) were from the Baby Boomer group (for details on generation cohort, please see Brosdahl and Carpenter, 2011). Additionally, 38.4 percent of respondents (highest percentage) were located in South India at the time of undertaking the survey. Also, 26 percent of respondents were located in North Indian, followed by 16.2 and 11.4 percent from Eastern and Western regions of India. The demographic characteristics of the respondents whose responses were considered for the final analysis are as provided in Table I.

Insert

Table I: Demographic Characteristics of the Sample $(\mathrm{N}=315)$

\subsection{Scales validation analysis}

Exploratory factor analysis (EFA) was undertaken for the three measures, and factors were extracted based on the acceptable estimates of "Kaiser-Meyer-Olkin" (KMO) measure of sample adequacy, "Barlett's test of sphericity" and significant level of ( $p<0.001)$. Eigenvalues $>1$, along with standard factor loadings $>0.5$, were considered in the current study (Field, 2009). For the mindfulness, the four items loaded on to one factor explaining 61.62 percent of the cumulative variance, and their standard factor loadings were in the range of .758-.811. One item was dropped because of factor loading $<0.5$. The KMO estimates for the sample adequacy was 0.779 (chi Square $=355.55, \mathrm{df}=6$ ), along with a significant result for the Barlett's test of sphericity $(p<0.001)$. For the empathy scale, all the three items loaded significantly to one factor explaining 71.86 percent of the cumulative variance, with standardized factor loadings in the range of .817-.859. The KMO estimates for the sample adequacy was 0.704 (chi Square $=305.35, \mathrm{df}=3$ ), along with the significant Barlett's test of 
sphericity results $(\mathrm{p}<0.001)$. The physical distancing scale kept its original structure, and both the items loaded significantly to a single factor explaining 84.27 percent of cumulative variance.The standard factor loadings of both the items were 918 . The KMO estimates for the sample adequacy was 0.800 (chi Square $=198.34$, $\mathrm{df}=1$ ), along with the Barlett's test of sphericity significant results $(\mathrm{p}<0.001)$.

\subsection{Descriptive analysis}

Individual's mindfulness indicated significant correlations with the other variables showed the highest correlation with physical distancing $(\mathrm{r}=0.471, p<0.01)$, and vice versa. Empathy showed the highest correlation with an individual's mindfulness $(r=0.372, p<$ 0.01) and vice versa. All the measures of the current study showed adequate Cronbach alpha $(>0.7)$. The descriptive statistics, namely mean and standard deviation along with the values of Cronbach alpha and correlations between the variables, are as shown in Table II.

\subsection{Confirmatory factor analysis}

Confirmatory factor analysis was conducted for the three constructs under consideration for the hypothesized model. The initial CFA results did not support the model fit, and one item of individual mindfulness was dropped. An item of individual mindfulness was dropped because it has high standardized residual covariance and large modification indices. The CFA outcome of the final measurement model with eight items supported the multiple indices of the model fit. The model fit indices outcomes viz. Chi-square/df $=2.199$, $\mathrm{CFI}=.977, \mathrm{TLI}=.963$, IFI $=.978$ and RMSEA $=.062$, suggested good fit and were considered (Hair et al., 1998, 2006).

Furthermore, standardized factor loading of all the items along with the Average Variance Extracted (AVE) was found to be higher than the acceptable range of 0.50 . For individual mindfulness, standardized factor loadings were in the range of $0.667-0.770$, for empathy, the range was $0.659-0.846$, and for physical distancing, between $0.737-0.930$. Moreover, Cronbach alpha and the Composite Reliability (CR) values were higher than the threshold value of 0.7 . Thus, these values support the convergent validity of the constructs in the current study (Fornell and Larcker, 1981). Additionally, the discriminant validity was confirmed by comparing the square root of the AVE (italics in diagonal) of each construct 
with that of the correlation coefficient of the other constructs. The AVE square root values were found to be higher than the correlation coefficients, supporting discriminant validity (Figueiro and Raufflet, 2015; Fornell and Larcker, 1981). Please refer to Table II for the details on alpha, CR, AVE, and the square root of AVE.

Please insert

Table II: Descriptive analysis, correlations and discriminant validity

Moreover, as suggested by the scholars (Bhattacharya and Sen, 2007; Podsakoff et al., 2003), CMB was examined using Harman's single factor score. The result suggested no CMB issues as the single factor explained only 36.15 percent (approx.) of the cumulative percent variance (which is $<$ than the acceptable threshold limit of 50 percent) (Akdogan and Cimsir, 2019; Podsakoff and Organ, 1986).

\subsection{Mediation analysis}

The relationship between an individual's mindfulness and physical distancing $(\mathrm{Hl})$ and an individual's mindfulness and empathy $(H 2)$ were examined for a direct relationship. Moreover, the mediating effect of empathy on the relationship between an individual's mindfulness and physical distancing (H3) was also observed. Model 4 of the PROCESS macro by Hayes (2017), along with the bootstrapping (5000 samples) method, was utilized for analysing mediation for the hypothesized model.

The analysis outcome showed that the individual's mindfulness is significantly and positively related to physical distancing $(\mathrm{B}=0.46, \mathrm{t}=7.65, \mathrm{p}<0.001$, please see Table III), and an individual's mindfulness was also found to be significantly and positively related to empathy ( $\mathrm{B}=0.43, \mathrm{t}=7.08, \mathrm{p}<0.001$, please see Table III). Thus, the findings of the analysis supported hypotheses $H 1$ and $H 2$. 
Furthermore, to test the hypothesis $H 3$, the association between individual's mindfulness and empathy $(\mathrm{B}=0.43, \mathrm{t}=7.08, \mathrm{p}<0.001$, please see Table III) along with that of empathy and physical distancing $(\mathrm{B}=0.17, \mathrm{t}=3.14, \mathrm{p}<0.001$, please see Table III) showed positive results. Moreover, a positive effect was noted for the direct relationship between an individual's mindfulness and physical distancing $(B=0.46, t=7.65, p<0.001$, please see Table III). Additionally, the bias-corrected estimate of the indirect effect of an individual's mindfulness on physical distancing $(B=0.07,95$ percent $C I[0.02,0.15]$, please see Table III) was found to be significant. Also, Sobel's test statistics outcome (Sobel Z = 3.080, $\mathrm{p}<0.01)$ confirmed significant indirect effect (Sobel, 1982). Thus, the mediation effect of the hypothesis $H 3$ is supported. Figure 1 shows the hypothesized model with results.

\section{Please insert}

Table III: Mediation analysis for physical distancing behaviour as the dependent variable

Please insert

Figure 1. The hypothesized model with results (value in parentheses shows indirect effect)

\section{Discussion}

The COVID-19 pandemic mars the present situation across the globe, and researchers, including the healthcare professional, are continually putting their best efforts to develop vaccines and find appropriate medicine to cure this viral disease. Government authorities, religious leaders, healthcare professionals, celebrities, and anyone and everyone who can influence the public are putting their best efforts and appealing to the general public to adhere to precautionary measures to avoid contacting COVID-19 disease. Despite the best efforts to curb the spread of the COVID-19 pandemic, the virus is spreading at a much faster rate and has infected more than 16.34 million and have killed 0.65 million people across 216 territories (as on $28^{\text {th }}$ July 2020, World Health Organization, 2020b). Against this background, physical distancing has emerged as a possible solution to slow down the spread 
of COVID-19 pandemic, and has been advocated by various stakeholders (authorities, politicians, healthcare professionals, celebrities, religious leaders, etc.) to the general public to adhere to.

The current study aimed to empirically determine the association between an individual's mindfulness and physical distancing behaviour at the time of COVID-19 pandemic, which has spread across the globe and is threatening the existence of humankind. The study utilized the quantitative method and the online survey technique was used to collect the responses from the general adult population living across all the six regions of India.

The results supported a direct relationship between an individual's mindfulness and physical distancing behaviour, i.e., an increase in an individual's mindfulness was found to be positively influencing the physical distancing behaviour at the time when the world is threatened by the COVID-19 pandemic. The results also support the intervening role of empathy on the association between an individual's mindfulness and physical distancing behaviour. These results are in agreement with the "reperceiving" mechanism of mindfulness (Shapiro et al., 2006) that states the role direct of mindfulness in influencing prosocial behaviours as well as the indirect influence through nurturing consciousness and by helping in recognizing and choose significant intrinsic values. Moreover, the findings are aligned with the existing studies supporting the role of mindfulness in encouraging prosocial behaviours (Berry et al., 2018; Donald et al., 2019; Flook et al., 2015; Hafenbrack et al., 2019), and also the mediating role of empathy in the positive association between mindfulness and prosocial behaviours (Berry et al., 2018; Dutton et al., 2014; Glomb et al., 2011; Hafenbrack et al., 2019). Additionally, the findings also add to the scant number of existing studies that have tried explicating the mechanism of mindfulness in other's oriented behaviours (Berry et al., 2018).

Moreover, the results of this study show the positive role of empathy in augmenting physical distancing behaviour, and also the intervening role of empathy in the relationship between mindfulness and physical distancing behaviour was noted. These results are well supported by extant theoretical arguments like that of the "empathy-altruism hypothesis" which states about the role of empathy in promoting the welfare of others (Batson, 2010), and also by Schwartz's theory of basic values wherein self-transcendence values are shown to be 
linked to empathy and welfare of others (Balliet et al., 2008; Myyrya et al., 2010; Pohling et al., 2016; Schwartz, 1992).

Thus, the present study contributes to the scant literature available in the area, trying to elucidate the role of human psychology in managing the spread of COVID-19 pandemic, especially by influencing and augmenting the role of the general public in adhering to physical distancing behaviour. The study is well-timed, and we have tried responding to the research call of scholars engaged in studying human psychology as well as other factors in managing the COVID-19 pandemic. We have tried addressing Pfattheicher et al. (2020) call to test human psychological factors that could influence physical distancing behaviour during the COVID-19 pandemic. Moreover, this study complements to the emerging area of research trying to explicate the factors that influence individuals' decision to adhere to physical distancing policy to manage the spread of COVID-19 pandemic (Allcott et al., 2020; Canning et al., 2020; Hsiang et al., 2020; Pennycook et al., 2020). Additionally, in a recent study on the Indian population during COVID-19 pandemic, Roy et al. (2020) have raised their concern about people not adhering to and ignoring the importance of "physical distancing." The results of the present study where in an individual's mindfulness showed a positive association with physical distancing behaviour could be helpful to motivate people in adhering to the physical distancing policy. This possible behaviour augmentation through mindfulness could be of some help in alleviating the concern raised by Roy et al. (2020) regarding the non-compliant behaviour of people towards physical distancing policy.

\section{Implications}

The present study explores the association between an individual's mindfulness, empathy,and physical distancing behaviour,and the results obtained could have useful implications for scholars as well as the policymakers.

\subsection{Theoretical contributions}

The conceptualization and the findings add to the existing scant literature in the domain trying to sneak into the human psychology that could be acting and augmenting the 
general public adhering to the physical distancing policy, which seems to have emerged as the primary line of defense to fight and check the spread of COVID-19 pandemic. To the best of our knowledge, this study is the first to conceptualize, empirically explore and extend the reperceiving mechanism of mindfulness in explaining individuals' physical distancing behaviour in the pandemic situation, notably the COVID-19 pandemic. Additionally, the "empathy-altruism hypothesis" (Batson, 2010), and Schwartz's theory of basic values (Schwartz, 1992) have been also explored and extended in explaining individuals' physical distancing behaviour in the pandemic situation. Moreover, this study complements to the emerging area of research trying to explain human psychological (Pfattheicher et al., 2020) as well as other factors (demographic, political, economic, etc.) (Allcott et al., 2020; Canning et al., 2020; Pennycook et al., 2020) that have been shown to influence individuals' behaviour to adhere to physical distancing policy to manage the spread of COVID-19 pandemic.

\subsection{Practical implications}

The results of the present study could prove to be a "holy grail" for the policymakers,healthcare authorities, and many others including government and nongovernment organizations and even corporate leaders who are responsible for and could be struggling for the successful implementation of physical distancing policy to mitigate the spread of COVID-19 pandemic. Extant scholarly work including empirical, meta-analytical, and systematic reviews across human psychology, consumer behaviour etc. domain have portrayed mindfulness as a universal and secular phenomenon which could be enhanced through various mindfulness-based programs (for details on different mindfulness-based programs, please refer to Birnie et al., 2010; Khoury et al., 2013; Khoury et al., 2015). Similarly, various researchers have noted the benefits of mindfulness-based programs in augmenting general public behaviour (Tang et al., 2013), including psychological welfare amongst fit and healthy individuals (Carmody and Baer, 2008; Chiesa and Serretti, 2009), and also in bringing down and helping individuals in coping with tension (Cachia et al., 2016). Moreover, the usefulness of mindfulness-based programs, both offline and online, have been tested across the different population and the findings were noted to be encouraging and positive (Ivtzan et al., 2016; Joyce et al., 2018; Morledge et al., 2013; Pflugeisen et al., 2016). Therefore, the dissemination of mindfulness-based programs, either through online or offline mode, amongst the general public could prove critical in the 
successful management of COVID-19 pandemic as it could help in promoting physical distancing behaviour, and people would adhere to the physical distancing policy.

At the policy intervention level, we suggest that various stakeholders of our society (government authorities, politicians, healthcare professionals, celebrities, religious leaders, etc.) should come together, appeal to the general public, help in the dissemination, and also encourage the adoption of mindfulness-based programs amongst the people. Mindfulness programs, either customized or already available, could be made accessible to the general public through smartphones, video-module, teleconference or combination (for details on mode of dissemination, please refer Fischer et al., 2020; Helmich and Bloem, 2020; Ivtzan et al., 2016; Joyce et al., 2018; Morledge et al., 2013; Pflugeisen et al., 2016). Authorities could look forward making use of various methods to disseminate mindfulness-based programs amongst the general public. Moreover, stress should be paid on online or physical contactless dissemination of mindfulness-based programs as it could serve the purpose of promoting the physical distancing behaviour along with adhering to the physical distancing policy.

Additionally, apart from augmenting physical distancing behaviour among the general population, mindfulness-based programs could also help in mitigating the negative consequences (like anxiety, fear, and stress) of the ongoing CORONA-19 pandemic (Fischer et al., 2020; Helmich and Bloem, 2020; Lindsay et al., 2019; Zheng et al., 2020). The uncertainty and the gloomy situation which has been created because of the COVID-19 pandemic has drastically effected the life of many across the globe, and mindfulness-based programs could be a way to fight anxiety and fear and could help people in relieving their day-to-day stress (Abramson Cancer Center, Penn Medicine, 2020; Mai, 2020; United Nation, 2020; Weiss, 2020).

Moreover, the outbreak of COVID-19 has posed unprecedented challenges to the corporates across the globe (Baker et al., 2020; Donthu and Gustafsson, 2020; Heand Harris, 2020), and the role of corporate leaders and change champions seem imperative in orchestrating turn around strategies to revive their organizations (Bodolica and Spraggon, 2020). A recent scholarly review published in this area has raised its concern about the lack of knowledge amongst the corporate leaders and change champions about such crisis management (Bodolica and Spraggon, 2020), and any research-based information which 
could help corporate leaders in the effective management of such a crisis could prove pivotal for the revival of the organizations.

In this vein, the findings of the present study could help corporate leaders and change champions in formulating strategies that would help in the effective management of COVID19 at the organization level, particularly the management of human resources. The decisionmakers in the organization could look forward to strategize and implement mindfulnessbased programs amongst their employees which would further help the employees in mitigating the risk and effective management of COVID-19 spread by adhering to physical distancing policy. Moreover, mindfulness-based programs could also help in alleviating other psychological issues like stress, anxiety, fear etc. amongst employees which could have crept in because of the COVID-19 pandemic crisis. Thus, knowledge about the application of mindfulness in managing the COVID-19 pandemic could be of much help to corporate leaders and change champions.

Thus, for the policymakers, healthcare authorities and even change champions at the corporate who are responsible for the successful management of COVID-19 pandemic, dissemination of mindfulness-based programs amongst individuals could prove to be a "holy grail". It would not only help in mitigating the risk of the spread of COVID-19 by promoting physical distancing behaviour but could also help in alleviating individuals from negative psychological issues like anxiety, fear, and stress that has secretly crept in the day to day life of people during COVID-19 pandemic.

\section{Limitations and future research directions}

As the findings of this study are based on the cross-sectional design, causality could not be established. Future research should go for longitudinal as well as experimental research designs helping in establishing the causal relationship amongst the constructs. Moreover, we have utilized convenience and snowball sampling techniques along with the self-reported survey approach, which has its limitations. Additionally, around 87 percent of the respondents belonged to the Gen Y/Millennial cohort. Thus, the results should be taken with caution. For better generalizability of the findings, more studies should be undertaken,especially in different cultural contexts amongst the general population utilizing different research designs. Future studies should also consider random sampling techniques 
for an extended generalization of the results. Moreover, in a few recent publications, mindfulness is discussed as a multidimensional concept and accordingly multidimensional measures have been developed. So, future studies could look for studying and try connecting physical distancing behaviour utilizing multidimensional concepts and scales of mindfulness (e.g. "Comprehensive Inventory of Mindfulness Experiences," scale, developed by Bergomiet al., 2013). Additionally, there could be more possible mediators and moderators influencing this relationship and should be explored.

Despite the above caveats, the results of this empirical study about the effect of an individual's mindfulness on physical distancing behaviour and the mediating role of empathy are encouraging for both scholars and practitioners. As mindfulness interventions could be disseminated amongst the general population helping them in augmenting their physical distancing behaviourto slow down the spread of COVID-19, it could be of much help in tackling this pandemic.

\section{Conclusion}

The present situation wherein the COVID-19 pandemic is spreading across the globe at a phenomenal rate,marred by the non-availability of vaccine or medicine to mitigate the spread or cureCOVID-19 seems scary. Moreover, extant scholars, as well as organizations like WHO and CDC, have advocated the adoption of a physical distancing policy (wherein individuals maintain a distance of 6 feet with others) amongst the general public to mitigate the spread of COVID-19 virus. In this vein, any human psychological approach that could augment physical distancing behaviour (known to slow down the spread of COVID-19 virus) would prove to be a "holy grail". Thus, based on the existing literature across the human psychology and behavioural domain, the present study tried to conceptualize and empirically explore the association between an individuals' mindfulness with that of physical distancing behaviour and also the intervening role of empathy (empathy towards individuals most susceptible to the coronavirus) in this relationship. The findings of the present study are encouraging and based on the all India survey responses from 315 respondents belonging to the general adult population, individual's mindfulness was noted to have a positive relationship with physical distancing behaviour. Moreover, empathy (empathy for those most susceptible to coronavirus COVID-19) was found to be mediating the relationship between mindfulness and physical distancing behavior. Thus, from the findings of the study, it could 
be concluded that an individual's mindfulness seems to promote physical distancing behaviour (a kind of prosocial behaviour), particularly in the case of the COVID-19 pandemic situation, and individual's mindfulness could act as a panacea in stalling the spread of this pandemic by promoting physical distancing behaviour amongst the general public. The findings of this study have both theoretical as well as practical implications. Apart from extending the role of mindfulness in managing pandemic, particularly by encouraging physical distancing behaviour amongst the general public in the case of COVID-19 context, the findings of this study could form the stepping stone for future research in this emerging area. Scholars working in the area of human psychology should feel encouraged to explore more on behavioural aspects of humans that could help in mitigating the risks of the present as well as a future pandemic. The results could also be of great help to policymakers and authorities responsible for tackling the pandemic issues and could encourage them in framing and disseminating various mindfulness-based programs which could further promote physical distancing behaviour amongst the general public for the management and slowing down the spread of COVID-19 pandemic. Similarly, the findings could also help corporate leaders and change champions in orchestrating strategies that would also incorporate mindfulness-based programs. Strategizing and successful implementation of mindfulness-based programs at the organizations could be helpful in the effective management of COVID-19 amongst employees and could also prove pivotal for the revival of the organizations.

\section{References}

Abramson Cancer Center, Penn Medicine. (2020), "How to use Mindfulness to Cope with COVID-19-Related Stressors",available at: https://www.pennmedicine.org/cancer/about/focus-on-cancer/2020/march/mindfulness (accessed 20 May 2020).

Akdogan, R. and Cimsir, E.(2019), "Linking inferiority feelings to subjective happiness: Self-concealment and loneliness as serial mediators", Personality and Individual Differences, Vol. 149, pp. 14-20.

Allcott, H., Boxell, L., Conway, J., Gentzkow, M., Thaler, M. andYang, D.Y.(2020), "Polarization and public health: Partisan differences in social distancing during the Coronavirus pandemic", NBER working paper, (w26946), available at:https://ssrn.com/abstract=3574415.

Anderson, R.M., Heesterbeek, H., Klinkenberg, D. and Hollingsworth, T.D.(2020), "How will country-based mitigation measures influence the course of the COVID-19 epidemic?", The Lancet, Vol. 395 No. 10228, pp. 931-934.

Bai, Y., Yao, L., Wei, T., Tian, F., Jin, D.Y., Chen, L. and Wang, M. (2020), "Presumed asymptomatic carrier transmission of COVID-19", JAMA, Vol. 323 No. 14, pp. 1406-1407.

Baker, S. R., Bloom, N., Davis, S. J., Kost, K., Sammon, M. and Viratyosin, T. (2020), “The unprecedented stock market reaction to COVID-19", The Review of Asset Pricing Studies, raaa008, https://doi.org/10.1093/rapstu/raaa008.

Balliet, D., Joireman, J., Daniels, D. and George-Falvy, J. (2008), "Empathy and the Schwartz Value System: A Test of an Integrated Hypothesis", Individual Differences Research, Vo. 6 No. 4, pp. 269-279.

Barnes, S., Brown, K.W., Krusemark, E., Campbell, W.K. and Rogge, R.D. (2007), "The role of mindfulness in romantic relationship satisfaction and responses to relationship stress", Journal of Marital and Family Therapy, Vol. 33 No. 4, pp. 482-500. 
Batson, C. D. (2010), "Empathy-induced altruistic motivation", M. Mikulincerand P. R. Shaver (Eds.), Prosocial motives, emotions, and behavior: The better angels of our nature, American Psychological Association, WashingtonDC, pp. 15-34.

Bellosta-Batalla, M., Blanco-Gandía, M.C., Rodríguez-Arias, M., Cebolla, A., Pérez-Blasco, J. and MoyaAlbiol, L.(2020), "Increased salivary oxytocin and empathy in students of clinical and health psychology after a mindfulness and compassion-based intervention”, Mindfulness, Vol. 11, pp. 1006-1017.

Bergomi, C., Tschacher, W. and Kupper, Z. (2013), "Measuring mindfulness: first steps towards the development of a comprehensive mindfulness scale", Mindfulness, Vol. 4 No. 1, pp. 18-32.

Berry, D.R., Cairo, A.H., Goodman, R.J., Quaglia, J.T., Green, J.D. and Brown, K.W. (2018), "Mindfulness increases prosocial responses toward ostracized strangers through empathic concern", Journal of Experimental Psychology: General, Vo.147 No. 1, pp. 93-112.

Birnie, K., Speca, M. and Carlson, L.E. (2010), "Exploring self-compassion and empathy in the context of mindfulness-based stress reduction (MBSR)", Stress and Health, Vol. 26 No. 5, pp. 359-371.

Block-Lerner, J., Adair, C., Plumb, J.C., Rhatigan, D.L. and Orsillo, S.M. (2007), "The case for mindfulnessbased approaches in the cultivation of empathy: Does nonjudgmental, present-moment awareness increase capacity for perspective-taking and empathic concern?",Journal of Marital \& Family Therapy, Vol. 33 No. 4 , pp. 501-516.

Bodolica, V. and Spraggon, M. (2020), "Leadership in times of organizational decline: a literature review of antecedents, consequences and moderators", International Journal of Organizational Analysis, https://doi.org/10.1108/IJOA-04-2020-2123.

Bootsma, M. C. and Ferguson, N. M. (2007), "The effect of public health measures on the 1918 influenza pandemic in US cities", Proceedings of the National Academy of Sciences, Vol. 104 No. 18, pp. 7588-7593.

Brosdahl, D.J. and Carpenter, J.M. (2011), "Shopping orientations of US males: A generational cohort comparison", Journal of Retailing and Consumer Services, Vol. 18 No. 6, pp. 548-554.

Brown, K.W. and Ryan, R.M. (2003), "The benefits of being present: Mindfulness and its role in psychological well-being”, Journal of Personality and Social Psychology, Vol. 84 No. 4, pp. 822-848.

Brzezinski, A., Kecht, V., Van Dijcke, D. andWright, A.L.(2020), "Belief in science influences physical distancing in response to covid-19 lockdown policies", working paper (2020-56), University of Chicago, Becker Friedman Institute for Economics, available at: https://ssrn.com/abstract=3587990 or http://dx.doi.org/10.2139/ssrn.3587990.

Bults, M., Beaujean, D.J., Richardus, J.H. and Voeten, H.A. (2015), "Perceptions and behavioral responses of the general public during the 2009 influenza A (H1N1) pandemic: a systematic review", Disaster Medicine and Public Health Preparedness, Vol. 9 No. 2, pp. 207-219.

Cachia, R. L., Anderson, A. and Moore, D. W. (2016), "Mindfulness, stress and well-being in parents of children with autism spectrum disorder: a systematic review”, Journal of Child and Family Studies, Vol. 25 No. 1, pp. 1-14.

Cahn, B. R. and Polich, J. (2006), "Meditation states and traits: EEG, ERP, and neuroimaging studies", Psychological Bulletin, Vol. 132 No. 2, pp. 180-211.

Caley, P., Philp, D. J. and McCracken, K. (2008), "Quantifying social distancing arising from pandemic influenza", Journal of the Royal Society Interface, Vol. 5 No. 23, pp. 631-639.

Canning, D., Karra, M., Dayalu, R., Guo, M. and Bloom, D.E. (2020), “The association between age, COVID19 symptoms, and social distancing behavior in the United States", available at:https://www.medrxiv.org/content/10.1101/2020.04.19.20065219v1.

Carlo, G., McGinley, M., Hayes, R. C. and Martinez, M. M. (2012), "Empathy as a mediator of the relations between parent and peer attachment and prosocial and physically aggressive behaviors in Mexican American college students", Journal of Social and Personal Relationships, Vol. 29 No. 3, pp. 337-357.

Carmody, J. and Baer, R. A. (2008), "Relationships between mindfulness practice and levels of mindfulness, medical and psychological symptoms and well-being in a mindfulness-based stress reduction program", Journal of Behavioral Medicine, Vol. 31 No. 1, pp. 23-33.

Centers for Disease Control and Prevention. (2020), "Transmission of Coronavirus Disease 2019 (COVID-19)", available at:https://www.cdc.gov/coronavirus/2019-ncov/prepare/transmission.html (accessed 22 May 2020). 
Chiesa, A. and Serretti, A. (2009), "Mindfulness-based stress reduction for stress management in healthy people: a review and meta-analysis", The Journal of Alternative and Complementary Medicine, Vol. 15 No. 5 , pp. 593-600.

Cohen, J. and Kupferschmidt K.(2020), “Countries test tactics in 'war' against COVID-19”, Science Vol. 367 No. 6484, pp. 1287-1288.

Condon, P., Desbordes, G., Miller, W. B. and DeSteno, D. (2013), "Meditation increases compassionate responses to suffering”, Psychological Science, Vol. 24 No. 10, pp. 2125-2127.

Davidson, R.J. and Harrington, A. (Eds.)(2002), Visions of Compassion: Western Scientists and Tibetan Buddhists Examine Human Nature, Oxford University Press, New York.

De Waal, F.B. (2008), "Putting the altruism back into altruism: the evolution of empathy", Annual Review of Psychology, Vol. 59, pp. 279-300.

Decety, J. and Ickes, W. (Eds.) (2011),The Social Neuroscience of Empathy, MIT Press, USA.

Dekeyser, M., Raes, F., Leijssen, M., Leysen, S. and Dewulf, D. (2008), "Mindfulness skills and interpersonal behavior", Personality and Individual Differences, Vol. 44 No. 5, pp. 1235-1245.

Delamater, P.L., Street, E.J., Leslie, T.F., Yang, Y.T. and Jacobsen, K.H.(2019), "Complexity of the basic reproduction number (R0)", Emerging Infectious Diseases, Vol. 25 No. 1, pp. 1-4.

Donald, J.N., Sahdra, B.K., Van Zanden, B., Duineveld, J.J., Atkins, P.W., Marshall, S.L. and Ciarrochi, J. (2019), "Does your mindfulness benefit others? A systematic review and meta-analysis of the link between mindfulness and prosocial behavior", British Journal of Psychology, Vol. 110 No. 1, pp. 101-125.

Donthu, N. and Gustafsson, A. (2020), "Effects of COVID-19 on business and research", Journal of Business Research, Vol. 117, pp. 284-289.

Dovidio, J. F., Allen, J. L. and Schroeder, D. A. (1990), "Specificity of empathy-induced helping: Evidence for altruistic motivation”, Journal of Personality and Social Psychology, Vol. 59 No. 2, pp. 249-260.

Du, S., Bhattacharya, C.B. and Sen, S. (2007), "Reaping relational rewards from corporate social responsibility: The role of competitive positioning", International Journal of Research in Marketing, Vol. 24 No. 3, pp. 224241.

Dutton, J.E., Workman, K.M. and Hardin, A.E. (2014), "Compassion at work", Annual Review of Organizational Psychology and Organizational Behavior, Vol. 1 No. 1, pp. 277-304.

Eisenberg, N. (2000), "Emotion, regulation, and moral development", Annual Review of Psychology, Vol. 51 No. 1, pp. 665-697.

Eisenberg, N., Fabes, R. and Spinrad, T. (2006), "Prosocial development", Damon, W., Lerner, R. M. and Eisenberg, N. (Eds.), Handbook of Child Psychology, Social, Emotional, and Personality Development, John Wiley \& Sons, New York, pp. 646-718.

Eisenberg, N. and Miller, P. A. (1987), "The relation of empathy to prosocial and related behaviors", Psychological Bulletin, Vol. 101 No. 1, pp. 91-119.

Ericson, T., Kjonstad, B.G. and Barstad, A. (2014), "Mindfulness and sustainability", Ecological Economics, Vol. 104, pp. 73-79.

Fan, Y., Duncan, N.W., de Greck, M. andNorthoff, G. (2011), "Is there a core neural network in empathy? An fMRI based quantitative meta-analysis", Neuroscience \&Biobehavioral Reviews, Vol. 35 No. 3, pp. 903-911.

Farb, N.A., Segal, Z.V., Mayberg, H., Bean, J., McKeon, D., Fatima, Z. and Anderson, A.K. (2007), “Attending to the present: mindfulness meditation reveals distinct neural modes of self-reference", Social Cognitive and Affective Neuroscience, Vol. 2 No. 4, pp. 313-322.

Ferguson, N.M., Laydon, D., Nedjati-Gilani, G., Imai, N., Ainslie, K. and Baguelin, M. (2020), "Impact of nonpharmaceutical interventions (NPIs) to reduce COVID-19 mortality and healthcare demand", available at: 
https://www.imperial.ac.uk/media/imperial-college/medicine/sph/ide/gida-fellowships/Imperial-CollegeCOVID19-NPI-modelling-16-03-2020.pdf (assessed 21May 2020).

Field, A. (2009), Discovering Statistics Using SPSS: Introducing Statistical Method, 3rd ed., Sage, Thousand Oaks, CA.

Figueiro, P.S. and Raufflet, E. (2015), "Sustainability in higher education: a systematic review with focus on management education", Journal of Cleaner Production, Vol. 106, pp. 22-33.

Fischer, R., Karl, J., Bortolini, T., Zilberberg, M., Robinson, K., Rabelo, A.L.A., ... Mattos, P. (2020), "Rapid review and meta-meta-analysis of self-guided interventions to address anxiety, depression and stress during COVID-19 social distancing", available at https://psyarxiv.com/ndyf4/.

Fisher, D. and Wilder-Smith, A.(2020), "The global community needs to swiftly ramp up the response to contain COVID-19), The Lancet, Vol. 395 No. 10230, pp. 1109-1110.

Flook, L., Goldberg, S.B., Pinger, L. and Davidson, R.J. (2015), "Promoting prosocial behavior and selfregulatory skills in preschool children through a mindfulness-based kindness curriculum", Developmental Psychology, Vol.51 No. 1, pp. 44-51.

Fong, M. W., Gao, H., Wong, J. Y., Xiao, J., Shiu, E. Y., Ryu, S. and Cowling, B. J. (2020), "Non pharmaceutical measures for pandemic influenza in non-healthcare settings-social distancing measures", Emerging Infectious Diseases, Vol. 26 No. 5, pp. 976-984.

Fornell, C. and Larcker, D.F. (1981), "Evaluating structural equation models with unobservable variables and measurement error",Journal of Marketing Research, Vol. 18 No. 1, pp. 39-50.

Gallicano, T.D., Curtin, P. and Matthews, K. (2012), "I love what I do, but... A relationship management survey of millennial generation public relations agency employees", Journal of Public Relations Research, Vol. 24 No. 3, pp. 222-242.

Glass, R. J., Glass, L. M., Beyeler, W. E. and Min, H. J. (2006), "Targeted social distancing designs for pandemic influenza", Emerging Infectious Diseases, Vol. 12 No. 11, pp. 1671-1681.

Glomb, T.M., Duffy, M.K., Bono, J.E. and Yang, T.(2011), "Mindfulness at work", Research in Personnel and Human Resources Management, Vol. 30 No. 1, pp. 115-157.

Good, D.J., Lyddy, C.J., Glomb, T.M., Bono, J.E., Brown, K.W., Duffy, M.K., ... Lazar, S.W. (2016), "Contemplating mindfulness at work: An integrative review", Journal of Management, Vol. 42 No. 1, pp. 114142.

Gostin, L.O. and Wiley, L.F. (2020), "Governmental public health powers during the COVID-19 pandemic: Stay-at-home orders, business closures, and travel restrictions", JAMA, Vol. 323 No. 21, pp. 2137-2138.

Granello, D.H. and Wheaton, J.E. (2004), "Online data collection: Strategies for research", Journal of Counselling \& Development, Vol.82 No. 4, pp. 387-393.

Grossman, P. (2015), "Mindfulness: awareness informed by an embodied ethic", Mindfulness, Vol.6 No. 1, pp. $17-22$.

Hafenbrack, A.C., Cameron, L.D., Spreitzer, G.M., Zhang, C., Noval, L.J. and Shaffakat, S. (2019), "Helping People by Being in the Present: Mindfulness Increases Prosocial Behavior", Organizational Behavior and Human Decision Processes, Vol. 159, pp. 21-38

Hair, J.F., Black, W.C., Babin, B.J., Anderson, R.E. and Tatham, R.L. (1998), Multivariate data analysis, Vol. 5,Prentice hall, Upper Saddle River, NJ.

Hair, J.F., Black, W.C., Babin, B.J., Anderson, R.E. and Tatham, R.L. (2006), Multivariate data analysis, Vol. 6, Prentice Hall, Upper Saddle River, N.J.

Hayes, A.F. (2017), Introduction to mediation, moderation, and conditional process analysis: A regressionbased approach, Guilford publications, New York, NY.

He, H. and Harris, L. (2020), "The Impact of Covid-19 Pandemic on Corporate Social Responsibility and Marketing Philosophy", Journal of Business Research, Vol. 116, pp. 176-182.

Helmich, R.C. and Bloem, B.R. (2020), "The impact of the COVID-19 pandemic on Parkinson's disease: Hidden sorrows and emerging opportunities", Journal of Parkinson's disease, Vol. 10 No. 2, pp. 351-354.

Hewson, C. and Charlton, J.P. (2005), "Measuring health beliefs on the Internet: A comparison of paper and Internet administrations of the Multidimensional Health Locus of Control Scale", Behavior Research Methods, Vol.37 No. 4, pp. 691-702.

Holshue, M.L., DeBolt, C., Lindquist, S., Lofy, K.H., Wiesman, J., Bruce, H., ... Diaz, G. (2020), "First case of 2019 novel coronavirus in the United States", New England Journal of Medicine, Vol. 382, pp. 929-936. 
Holzel, B.K., Lazar, S.W., Gard, T., Schuman-Olivier, Z., Vago, D.R. and Ott, U. (2011), "How does mindfulness meditation work? Proposing mechanisms of action from a conceptual and neural perspective", Perspectives on Psychological Science, Vo. 6 No. 6, pp. 537-559.

Hsiang, S., Allen, D., Annan-Phan, S., Bell, K., Bolliger, I., Chong, T., Druckenmiller, H., Huang, L.Y., Hultgren, A., Krasovich, E. and Lau, P. (2020), "The effect of large-scale anti-contagion policies on the COVID-19 pandemic", Nature, pp.1-9.

Ivtzan, I., Young, T., Martman, J., Jeffrey, A., Lomas, T., Hart, R. and Eiroa-Orosa, F. J. (2016), "Integrating mindfulness into positive psychology: A randomised controlled trial of an online positive mindfulness program", Mindfulness, Vol. 7 No. 6, pp. 1396-1407.

Jazaieri, H., McGonigal, K., Jinpa, T., Doty, J.R., Gross, J.J. and Goldin, P.R. (2014), “A randomized controlled trial of compassion cultivation training: Effects on mindfulness, affect, and emotion regulation", Motivation and Emotion, Vol. 38 No. 1, pp. 23-35.

Joyce, S., Shand, F., Bryant, R. A., Lal, T. J. and Harvey, S. B. (2018), "Mindfulness-based resilience training in the workplace: pilot study of the internet-based Resilience@ Work (RAW) mindfulness program", Journal of Medical Internet Research, Vol. 20 No. 9, e10326.

Kabat-Zinn, J. (1990). Full catastrophe living: Using the wisdom of your body and mind to face stress, pain, and illness, Delacorte, New York.

Kabat-Zinn, J. (1994), Wherever you go, there you are: mindfulness meditation in everyday life, Hyperion, New York.

Kabat-Zinn, J. (2003), "Mindfulness-based interventions in context: past, present, and future", Clinical psychology: Science and Practice, Vol.10 No. 2, pp. 144-156.

Khoury, B., Knauper, B., Schlosser, M., Carriere, K. and Chiesa, A. (2017), "Effectiveness of traditional meditation retreats: A systematic review and meta-analysis", Journal of Psychosomatic Research, Vol. 92, pp. $16-25$.

Khoury, B., Lecomte, T., Fortin, G., Masse, M., Therien, P., Bouchard, V. ...Hofmann, S. G. (2013), "Mindfulness-based therapy: a comprehensive meta-analysis", Clinical Psychology Review, Vol. 33 No. 6, pp. 763-771.

Khoury, B., Sharma, M., Rush, S. E. and Fournier, C. (2015), "Mindfulness-based stress reduction for healthy individuals: A meta-analysis” Journal of Psychosomatic Research, Vol. 78 No. 6, pp. 519-528.

King, D.B., O'Rourke, N. and DeLongis, A. (2014), "Social media recruitment and online data collection: A beginner's guide and best practices for accessing low-prevalence and hard-to-reach populations", Canadian Psychology/Psychologie Canadienne, Vol. 55 No. 4, pp. 240-249.

Klimecki, O.M., Leiberg, S., Lamm, C. and Singer, T. (2013), "Functional neural plasticity and associated changes in positive affect after compassion training”, Cerebral Cortex, Vol. 23 No. 7, pp. 1552-1561.

Krasner, M.S., Epstein, R.M., Beckman, H., Suchman, A.L., Chapman, B., Mooney, C.J. and Quill, T.E. (2009), "Association of an educational program in mindful communication with burnout, empathy, and attitudes among primary care physicians", JAMA, Vol. 302 No. 12, pp. 1284-1293.

Kristeller, J.L. and Johnson, T. (2005), "Cultivating loving kindness: A two-stage model of the effects of meditation on empathy, compassion, and altruism", Journal of Religion and Science, Vol. 40 No. 2, pp. 391408.

Langer, E. J. (2007), On becoming an artist: Reinventing yourself through mindful creativity, Ballantine Books, New York.

Lewnard, J.A. and Lo, N.C. (2020), "Scientific and ethical basis for social-distancing interventions against COVID-19", The Lancet. Infectious Diseases, Vol.20 No. 6,pp. 631-633.

Lim, D., Condon, P. and DeSteno, D. (2015), "Mindfulness and compassion: an examination of mechanism and scalability", PloS one, Vol. 10 No. 2, e0118221. 
Lindsay, E.K., Young, S., Brown, K.W., Smyth, J.M. and Creswell, J.D. (2019), "Mindfulness training reduces loneliness and increases social contact in a randomized controlled trial", Proceedings of the National Academy of Sciences, Vol. 116 No. 9, pp. 3488-3493.

Liu, M. and Wronski, L. (2018), "Examining completion rates in web surveys via over 25,000 real-world surveys", Social Science Computer Review, Vol. 36 No. 1, pp. 116-124.

Liu, Y., Gayle, A. A., Wilder-Smith, A. and Rocklov, J. (2020), "The reproductive number of COVID-19 is higher compared to SARS coronavirus", Journal of Travel Medicine, Vol. 27 No. 2, pp. 1-4.

Long, N.J. (2020), "From social distancing to social containment: reimagining sociality for the coronavirus pandemic", Medicine Anthropology Theory, available at:http://eprints.lse.ac.uk/103801/.

Luberto, C. M., Shinday, N., Song, R., Philpotts, L. L., Park, E. R., Fricchione, G. L. and Yeh, G. Y. (2018), “A systematic review and meta-analysis of the effects of meditation on empathy, compassion, and prosocial behaviors", Mindfulness, Vol. 9 No. 3, pp. 708-724.

Mahase, E. (2020), "Covid-19: UK starts social distancing after new model points to 260000 potential deaths", $B M J, 368: \mathrm{m} 1089$.

Mai, T. (2020), “WHY PRACTICE MINDFULNESS DURING A PANDEMIC?”, Health, University of Utah, available at: https://healthcare.utah.edu/healthfeed/postings/2020/04/mindfulness-coronavirus.php (accessed 20May 2020).

McCloskey, B., Zumla, A., Ippolito, G., Blumberg, L., Arbon, P., Cicero, A., ... Borodina, M. (2020), "Mass gathering events and reducing further global spread of COVID-19: a political and public health dilemma", The Lancet, Vol. 395 No. 10230, pp. 1096-1099.

McMahon, S. D., Wernsman, J. and Parnes, A. L. (2006), "Understanding prosocial behavior: The impact of empathy and gender among African American adolescents", Journal of Adolescent Health, Vol. 39 No. 1, pp. 135-137.

Milne, G.J. and Xie, S. (2020), "The effectiveness of social distancing in mitigating COVID-19 spread: a modelling analysis", available at https://www.medrxiv.org/content/10.1101/2020.03.20.20040055v1.

Morelli, S. A., Rameson, L. T. and Lieberman, M. D. (2014), "The neural components of empathy: predicting daily prosocial behavior", Social Cognitive and Affective Neuroscience, Vol. 9 No. 1, pp. 39-47.

Morledge, T. J., Allexandre, D., Fox, E., Fu, A. Z., Higashi, M. K., Kruzikas, D. T. ...Reese, P. R. (2013), "Feasibility of an online mindfulness program for stress management-a randomized, controlled trial", Annals of Behavioral Medicine, Vol. 46 No. 2, pp. 137-148.

Myyrya, L., Juujarvi, S. and Pesso, K. (2010), "Empathy, perspective taking and personal values as predictors of moral schemas", Journal of Moral Education, Vol. 39 No. 2, pp. 213-233.

Neff, K.D. (2003), "The development and validation of a scale to measure self-compassion", Self and Identity, Vol. 2 No. 3, pp. 223-250.

Padilla-Walker, L. M. and Christensen, K. J. (2011), "Empathy and self-regulation as mediators between parenting and adolescents' prosocial behavior toward strangers, friends, and family", Journal of Research on Adolescence, Vol. 21 No. 3, pp. 545-551.

Painter, M. and Qiu T. (2020), "Political Beliefs affect Compliance with COVID-19 Social Distancing Orders", available at: https://ssrn.com/abstract=3569098 or http://dx.doi.org/10.2139/ssrn.3569098

Pennycook, G., McPhetres, J., Bago, B. and Rand, D. (2020), "Predictors of attitudes and misperceptions about COVID-19 in Canada, the UK, and the USA", working paper, available at https://osf.io/3a497/.

Pfattheicher, S., Nockur, L., Bohm, R., Sassenrath, C. and Petersen, M.B. (2020), "The emotional path to action: Empathy promotes physical distancing during the COVID-19 pandemic", working paper, available at https://psyarxiv.com/y2cg5/.

Pfattheicher, S., Sassenrath, C. and Keller, J. (2019), "Compassion magnifies third-party punishment”, Journal of Personality and Social Psychology, Vol. 117 No. 1, pp. 124-141.

Pflugeisen, B. M., Drummond, D., Ebersole, D., Mundell, K. and Chen, D. (2016), "Brief video-module administered mindfulness program for physicians: a pilot study", Explore, Vol. 12 No. 1, pp. 50-54.

Podsakoff, P.M. and Organ, D.W. (1986), "Self-reports in organizational research: Problems and prospects", Journal of Management, Vol. 12 No. 4, pp. 531-544.

Podsakoff, P.M., MacKenzie, S.B., Lee, J.Y. and Podsakoff, N.P. (2003), "Common method biases in behavioral research: A critical review of the literature and recommended remedies", Journal of Applied Psychology, Vol. 88 No. 5, pp. 879-903.

Pohling, R., Bzdok, D., Eigenstetter, M., Stumpf, S. and Strobel, A. (2016), "What is ethical competence? The role of empathy, personal values, and the five-factor model of personality in ethical decision-making", Journal of Business Ethics, Vol. 137 No. 3, pp. 449-474.

Poletti, P., Caprile, B., Ajelli, M., Pugliese, A. and Merler, S. (2009), "Spontaneous behavioural changes in response to epidemics", Journal of Theoretical Biology, Vol. 260 No. 1, pp. 31-40. 
Prot, S., Gentile, D.A., Anderson, C.A., Suzuki, K., Swing, E., Lim, K.M., ... Liau, A.K. (2014), "Long-term relations among prosocial-media use, empathy, and prosocial behavior", Psychological Science, Vol. 25 No. 2 , pp. 358-368.

Raat, H., Mangunkusumo, R.T., Landgraf, J.M., Kloek, G. and Brug, J. (2007), "Feasibility, reliability, and validity of adolescent health status measurement by the Child Health Questionnaire Child Form (CHQ-CF): internet administration compared with the standard paper version", Quality of Life Research, Vol.16 No. 4, pp. 675-685.

Reiter, L. (2015), "Investigating the role of social networking sites in increasing purchase intention for environmentally sustainable apparel: An exploratory study", doctoral dissertation, Kansas State University, available at:http://hdl.handle.net/2097/19004.

Richaud, M.C., Lemos, V.N., Mesurado, B. and Oros, L. (2017), "Construct validity and reliability of a new Spanish empathy questionnaire for children and early adolescents”, Frontiers in Psychology, 8:979.

Ridderinkhof, A., de Bruin, E.I., Brummelman, E. and Bogels, S.M. (2017), "Does mindfulness meditation increase empathy? An experiment", Self and Identity, Vol. 16 No. 3, pp. 251-269.

Roccas, S., Sagiv, L., Schwartz, S. H. and Knafo, A. (2002), "The big five personality factors and personal values", Personality and Social Psychology Bulletin, Vol. 28 No. 6, pp. 789-801.

Roy, D., Tripathy, S., Kar, S.K., Sharma, N., Verma, S.K. and Kaushal, V. (2020), "Study of knowledge, attitude, anxiety \& perceived mental healthcare need in Indian population during COVID-19 pandemic", Asian Journal of Psychiatry, Vol. 51 No. 102083.

Schwartz, S. H. (1992), "Universals in the content and structure of values: Theoretical advances and empirical tests in 20 countries", M. P. Zanna (Ed.) Advances in Experimental Social Psychology, Academic Press, New York, pp. 1-65,

Schwartz, S. H. (1994), “Are there universal aspects in the structure and contents of human values?", Journal of Social Issues, Vol. 50 No. 4, pp. 19-45.

Sen-Crowe, B., McKenney, M. and Elkbuli, A. (2020), "Social distancing during the COVID-19 pandemic: Staying home save lives", The American Journal of Emergency Medicine, article in press, available at https:/www.ajemjournal.com/action/showPdf?pii=S0735-6757\%2820\%2930221-7.

Shapiro, S.L., Brown, K. W., Thoresen, C. and Plante, T.G. (2011), "The moderation of mindfulness-based stress reduction effects by trait mindfulness: results from a randomized controlled trial", Journal of Clinical Psychology, Vol. 67 No. 3, pp. 267-277.

Shapiro, S.L., Carlson, L.E., Astin, J.A. and Freedman, B. (2006), "Mechanisms of mindfulness", Journal of Clinical Psychology, Vol.62 No. 3, pp. 373-386.

Shapiro, S.L., Schwartz, G.E. and Bonner, G. (1998), "Effects of mindfulness-based stress reduction on medical and premedical students", Journal of Behavioral Medicine, Vol. 21, pp. 581-599.

Siegel, D.J. (2007), The mindful brain: Reflection and attunement in the cultivation of well-being, Norton series on interpersonal neurobiology, WW Norton \& Company, New York.

Sobel, M.E. (1982), "Asymptotic confidence intervals for indirect effects in structural equations models", Leinhardt, S. (Ed.), Sociological Methodology, Jossey-Bass Publishers, San Francisco, CA, pp. 290-312.

Tan, L.B., Lo, B.C. and Macrae, C.N. (2014), "Brief mindfulness meditation improves mental state attribution and empathizing", PLoS One, Vol. 9 No. 10, e110510.

Tang, Y. Y., Tang, R. and Posner, M. I. (2013), "Brief meditation training induces smoking reduction", Proceedings of the National Academy of Sciences, Vol. 110 No. 34, pp. 13971-13975.

Telle, N. T. and Pfister, H. R. (2016), "Positive empathy and prosocial behavior: A neglected link", Emotion Review, Vol. 8 No. 2, pp. 154-163.

Times of India (2020), “Controlling Coronavirus Spread Could Take 4-5 Years, Can't Depend On A COVID-19 Vaccine Alone, Says WHO Scientist", available at: https://timesofindia.indiatimes.com/life-style/healthfitness/health-news/coronavirus-vaccine-covid-19-spread-latest-news-update-controlling-coronavirus-spread- 
could-take-4-5-years-cant-depend-on-a-covid-19-vaccine-alone-says-who-scientist/photostory/75759992.cms

(accessed 17 May 2020).

Trautwein, F. M., Naranjo, J. R. and Schmidt, S. (2014), "Meditation effects in the social domain: self-other connectedness as a general mechanism?,S. Schmidt and H. Walach (Eds.), Meditation-neuroscientific approaches and philosophical implications, Springer, Cham, pp. 175-198.

Trousselard, M., Steiler, D., Claverie, D. and Canini, F. (2014), "The history of mindfulness put to the test of current scientific data: Unresolved questions", Encephale, Vol.40 No. 6, pp. 474-480.

United Nation (2020), "Wellbeing tips for UN Personnel. United Nations, COVID-19 Response", available at: https://www.un.org/en/coronavirus/wellness (accessed 20 May 2020).

Vago, D. R. and Silbersweig, D. A. (2012), "Self-awareness, self-regulation, and self-transcendence (S-ART): a framework for understanding the neurobiological mechanisms of mindfulness", Frontiers in Human Neuroscience, Vol. 6, No. 296, pp. 1-30.

Van Dam, N. T., Earleywine, M. and Borders, A. (2010), "Measuring mindfulness? An item response theory analysis of the Mindful Attention Awareness Scale", Personality and Individual Differences, Vol. 49No. 7, pp. 805-810.

Wallace, E., Buil, I. and de Chernatony, L. (2017), "When does "liking" a charity lead to donation behavior? Exploring conspicuous donation behavior on social media platforms", European Journal of Marketing, Vol. 51 No. 11/12, pp. 2002-2029.

Wallmark, E., Safarzadeh, K., Daukantaite, D. and Maddux, R. E. (2013), "Promoting altruism through meditation: an 8-week randomized controlled pilot study", Mindfulness, Vol. 4 No. 3, pp. 223-234.

Weiss, C. (2020), "COVID-19: Tips for Mindfulness \& Coping with Anxiety", available at:https://newsnetwork.mayoclinic.org/discussion/covid-19-tips-for-mindfulness-coping-with-anxiety/ (accessed 25 May 2020).

World Health Organization (2020a), "Rolling Updates on Coronavirus Disease (COVID-19)", available at: https://www.who.int/emergencies/diseases/novel-coronavirus-2019/events-as-they-happen (accessed 22 May 2020).

World Health Organization (2020b), "Coronavirus disease (COVID-19) outbreak situation", available at: https://www.who.int/emergencies/diseases/novel-coronavirus-2019 (accessed 29 July 2020).

Wilder-Smith, A., Chiew, C.J. and Lee, V.J. (2020), "Can we contain the COVID-19 outbreak with the same measures as for SARS?", The Lancet Infectious Diseases, Vol. 20 No. 5, pp. e102-e107.

Williams, A., O'Driscoll, K. and Moore, C. (2014), “The influence of empathic concern on prosocial behavior in children", Frontiers in Psychology, Vol. 5, No. 425, pp. 1-8.

Winning, A. P. and Boag, S. (2015), "Does brief mindfulness training increase empathy? The role of personality”, Personality and Individual Differences, Vol. 86, pp. 492-498.

Wright, A.L., Sonin, K., Driscoll, J. and Wilson, J. (2020), "Poverty and economic dislocation reduce compliance with covid-19 shelter-in-place protocols", working paper (2020-40), University of Chicago, Becker Friedman Institute for Economics, available at: https://ssrn.com/abstract $=3573637$ or http://dx.doi.org/10.2139/ssrn.3573637

Zhang, Y. and Ma, Z.F. (2020), "Impact of the COVID-19 pandemic on mental health and quality of life among local residents in Liaoning Province, China: A cross-sectional study", International Journal of Environmental Research and Public Health, Vol. 17 No. 7, p. 2381.

Zheng, M.X., Yao, J. and Narayanan, J. (2020), "Mindfulness Buffers the Impact of COVID-19 Outbreak Information on Sleep Duration", available at https://psyarxiv.com/wuh94/. 


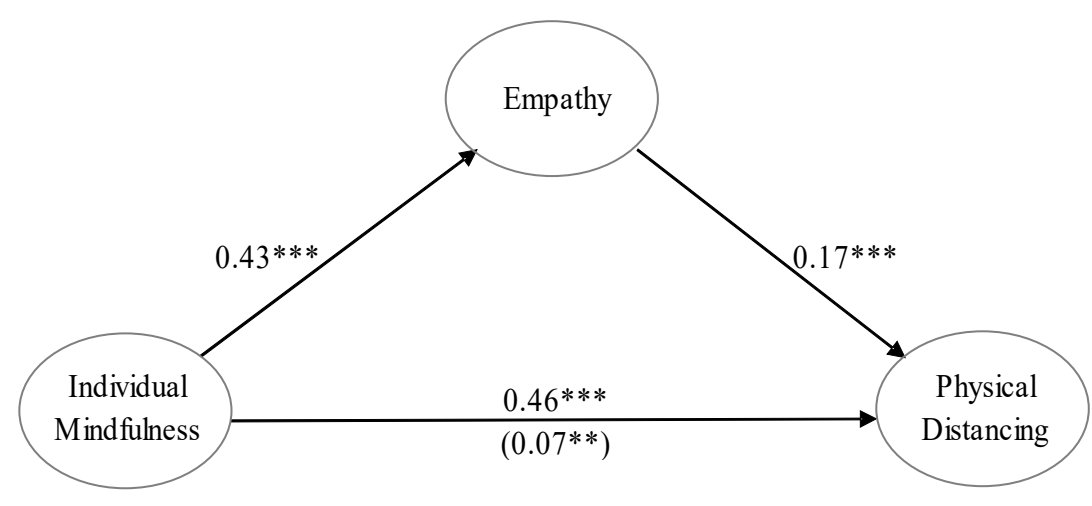

Figure 1. The hypothesized model with results (value in parentheses shows indirect effect)

\begin{tabular}{|c|c|c|c|}
\hline \multicolumn{2}{|c|}{ Variable- Description } & $\mathbf{N}$ & $\%$ \\
\hline \multirow{2}{*}{ Gender } & Male & 220 & 69.8 \\
\hline & Female & 95 & 30.2 \\
\hline \multirow{3}{*}{ Generation Cohort } & Gen Y/Millennial & 273 & 86.7 \\
\hline & Gen X & 40 & 12.7 \\
\hline & Baby Boomer & 2 & 0.6 \\
\hline \multirow{6}{*}{ Present Location } & East & 51 & 16.2 \\
\hline & West & 36 & 11.4 \\
\hline & North & 82 & 26.0 \\
\hline & South & 121 & 38.4 \\
\hline & Central & 12 & 3.8 \\
\hline & North-East & 13 & 4.2 \\
\hline $\begin{array}{l}\text { Note: Gen Y/Millennial } \\
\text { born in between }(1980- \\
1946) \text {. }\end{array}$ & $\begin{array}{l}\text { rt born in between }(1 \\
\text { and Baby Boomer - th }\end{array}$ & $\begin{array}{l}81), G \\
\text { oorn in }\end{array}$ & $\begin{array}{l}\text { the grou } \\
\text { n (1960 }\end{array}$ \\
\hline
\end{tabular}

Table I: Demographic Characteristics of the Sample $(\mathrm{N}=315)$ 


\begin{tabular}{|lccccccccc|}
\hline & Mean & Std. Dev. & $\begin{array}{c}\text { Cronbach } \\
\text { alpha }\end{array}$ & CR & AVE & 1 & 2 & 3 \\
\hline Individual Mindfulness & 4.01 & 0.65 & 0.702 & 0.760 & 0.514 & 0.717 & \\
Empathy & 4.02 & 0.77 & 0.803 & 0.803 & 0.578 & $.372^{* *}$ & 0.760 & \\
Physical Distancing & 4.49 & 0.76 & 0.813 & 0.824 & 0.704 & $.471^{* *}$ & $.331^{* *}$ & 0.839 \\
Note** $p<0.01$ level (2-tailed); the italics numbers at the end of each row are square roots of AVE & & & \\
\hline
\end{tabular}

Table II: Descriptive analysis, correlations and discriminant validity

\begin{tabular}{|c|c|c|c|c|}
\hline \multicolumn{5}{|c|}{ Direct effect } \\
\hline Predictor & Outcome & $\mathrm{B}(\mathrm{SE})$ & $95 \% \mathrm{CI}$ & $t$-value \\
\hline Individual Mindfulness (X) & Empathy (M) & $0.43(0.06)$ & {$[0.31,0.55]$} & $7.08 * * *$ \\
\hline Empathy (M) & Physical Distancing (Y) & $0.17(0.05)$ & {$[0.07,0.28]$} & $3.41 * * *$ \\
\hline Individual Mindfulness (X) & Physical Distancing (Y) & $0.46(0.06)$ & {$[0.34,0.58]$} & $7.65 * * *$ \\
\hline \multicolumn{5}{|c|}{ Indirect effect } \\
\hline Predictor & Mediator & Outcome & $\mathrm{B}(\mathrm{SE})$ & $95 \% \mathrm{CI}$ \\
\hline Individual Mindfulness (X) & Empathy (M) & Physical Distancing (Y) & $0.07(0.03)$ & {$[0.02,0.15]$} \\
\hline \multicolumn{5}{|c|}{ Indirect effect (Sobel Test) } \\
\hline Predictor & Mediator & Outcome & $\mathrm{B}(\mathrm{SE})$ & $\mathrm{Z}$ \\
\hline Individual Mindfulness (X) & Empathy (M) & Physical Distancing (Y) & $0.07(0.03)$ & $3.080 * *$ \\
\hline
\end{tabular}

Table III: Mediation analysis for physical distancing behaviour as the dependent variable

\section{Appendix 1}

Survey Instrument

Please provide the following demographic information. 
1. Indicate your gender.

Male Female

2. You are born between which of the following years?

$1999-1981 \quad 1980-1961 \quad 1960-1946$

3. Please indicate, you are located in which part/region of India?

East West North South Central North-East

Below are statements about your everyday experience. Please indicate how often you currently have eachexperience. Answer what really reflects your experience rather than what you think your experience should be.Please remember, there are no right or wrong answers.

1. It seems I am "running on automatic" without much awareness of what I'm doing.

2. I rush through activities without being attentive to them.

3. I get so focused on the goal I want to achieve that I lose touch with what I am doing right now to get there.

4. I do jobs or tasks automatically, without being aware of what I'm doing.

5. I find myself doing things without paying attention.

Type the name of the fruit you like most.....

Please answer the following questions honestly and quickly. Please remember, there is no right or wrong answer.

1. I am very concerned about those most vulnerable to coronavirus COVID 19.

2. I feel compassion for those most vulnerable to coronavirus COVID 19.

3. I am quite moved by what can happen to those most vulnerable to coronavirus COVID 19.

Please answer the following questions honestly and quickly. Please remember, there is no right or wrong answer.

1. Because of coronavirus COVID-19, I am massively curtailing social contact (so-called "social distancing").

2. Because of coronavirus COVID-19, it is very important that others massively curtail social contact (socalled "social distancing").

Note: Respondents were asked to record their responses on a 5-point Likert scale $(1=$ never; $5=$ always $)$. 